\title{
Screening for Latent Tuberculosis in Children With Immune-Mediated Inflammatory Diseases Treated With Anti-Tumor Necrosis Factor Therapy: Comparison of Tuberculin Skin and T-SPOT Tuberculosis Tests
}

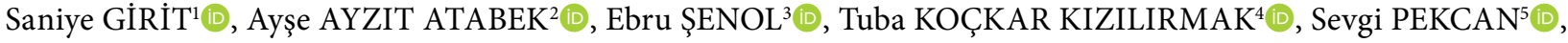

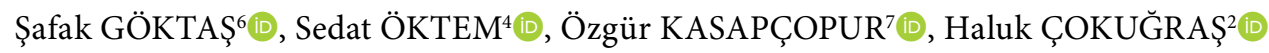 \\ ${ }^{1}$ Department of Pediatric Pulmonology, Medeniyet University Medical School Goztepe Training and Research Hospital, Istanbul, Turkey \\ ${ }^{2}$ Department of Pediatric Pulmonology, Istanbul University Cerrahpaşa Medical School, Istanbul, Turkey \\ ${ }^{3}$ Department of Pediatrics, University of Health Sciences, Dr. Lütfi Kırdar Training and Research Hospital, Istanbul, Turkey \\ ${ }^{4}$ Department of Pediatric Pulmonology, Medipol University Medical School, Istanbul, Turkey \\ ${ }^{5}$ Department of Pediatric Pulmonology, Konya Necmettin Erbakan University Meram Medical School, Konya, Turkey \\ ${ }^{6}$ Gelişim Medical Laboratories, Infectious Diseases and Microbiology, Istanbul, Turkey \\ ${ }^{7}$ Department of Pediatric Rheumatology, Istanbul University Cerrahpaşa Medical School, Istanbul, Turkey
}

\begin{abstract}
Objectives: This study aims to analyze the coherence between T-SPOT tuberculosis test (T-SPOT.TB) and tuberculin skin test (TST) with different cut-off values in screening latent tuberculosis infection (LTBI) both prior to and at the sixth month of anti-tumor necrosis factor (anti-TNF) treatment. Patients and methods: This prospective multicentric study included 57 children (34 girls, 23 boys, mean age $12.4 \pm 3.9$ years; range, 6 to 18 years) diagnosed with immune-mediated inflammatory diseases (IMIDs) evaluated with TST and T-SPOT.TB for screening LTBI both prior to and at the sixth month of treatment with anti-TNF agents. Coherence between two tests was analyzed for TST cut-off values suggested by the local guidelines and also for different possible cut-off values of TST.

Results: Tuberculin skin test was positive $(\geq 5 \mathrm{~mm})$ in $28.1 \%(n=16)$ of patients in the screening prior to treatment and in $33.3 \%$ ( $n=19)$ at the sixth month of treatment. T-SPOT.TB test was positive in $8.8 \%(n=5)$ of patients both prior to and at the sixth month of treatment. Coherence between two tests was poor or fair when compared with all possible TST cut-off values both prior to and at the sixth month of anti-TNF therapy.

Conclusion: Our results show poor coherence between T-SPOT.TB and TST for all possible cut-off values of TST. Thus, using both tests would be beneficial in screening LTBI until further studies bring new evidence on the subject.

Keywords: Child, immune system disease, interferon-gamma release assay, latent tuberculosis, tuberculin skin test.
\end{abstract}

Anti-tumor necrosis factor-alpha (anti-TNF- $\alpha$ ) drugs are biological agents used in the treatment of rheumatic diseases resistant to disease-modifying antirheumatic drugs (DMARDs). ${ }^{1}$ Anti-TNF drug use in the treatment of inflammatory diseases is increasing every day; however, these agents also bring out the risk for opportunistic infections like tuberculosis (TB). ${ }^{2}$ Particularly in countries with high prevalence of $\mathrm{TB}$, activation of latent tuberculosis infection (LTBI) is an important

Received: November 15, 2018 Accepted: April 04, 2019 Published online: June 25, 2019

Correspondence: Ebru Şenol, MD. Kartal Dr. Lütfi Kırdar Eğitim ve Araştırma Hastanesi Çocuk Sağlığı ve Hastalıkları Kliniği, 34890 Kartal, İstanbul, Turkey. Tel: +90533 - 3375657 e-mail: drebrusenol@gmail.com

\section{Citation:}

Girit S, Ayzıt Atabek A, Şenol E, Koçkar Kızılırmak T, Pekcan S, Göktaş \$̧, et al. Screening for Latent Tuberculosis in Children With Immune-Mediated Inflammatory Diseases Treated With Anti-Tumor Necrosis Factor Therapy: Comparison of Tuberculin Skin and T-Spot Tuberculosis Tests. Arch Rheumatol 2020;35(1):20-28. 
problem in the course of anti-TNF treatment. ${ }^{3}$ Screening for LTBI prior to anti-TNF treatment aims to detect patients with high risk to develop active TB infection and to treat the latent infection before it activates.

Recommendations on LTBI screening and diagnosis vary widely around the world; however, almost all guidelines suggest tuberculin skin test (TST), which itself has many disadvantages. ${ }^{4}$ TST has low specificity since it can be affected by Bacillus Calmette-Guérin (BCG) vaccination and exposure to environmental nontuberculous mycobacteria (NTM) causing false positive results. ${ }^{5}$ TST results are generally lower in patients with immune-mediated inflammatory diseases (IMIDs) because of the disease itself and/or use of immunosuppressive drugs. This low sensitivity can cause false negative results and risk activation of TB while using anti-TNF agents. Particularly in countries with routine vaccination for $\mathrm{TB}$, using TST alone may cause both false positive and false negative results and probable complications. ${ }^{6,7}$

Because of these disadvantages of TST, more specific and sensitive tests are needed. ${ }^{8}$ Interferon-gamma release assays (IGRAs) are the principal tests in this area. IGRAs measure the gamma $(\gamma)$ interferon levels secreted by T-lymphocytes against Mycobacterium tuberculosis (M.tuberculosis) in infected people. Specific proteins of M.tuberculosis, which are not found in BCG vaccine and most of the NTM are used in IGRAs. ${ }^{9,10}$ Therefore; the test can distinguish the vaccinated individuals, NTM infections and the TB infection. There are two tests which can measure T-cell $\gamma$ interferon release: T-SPOT tuberculosis (T-SPOT.TB) test and QuantiFERON-TB Gold In-Tube (QFT-GIT). Sensitivity and specificity of T-SPOT.TB have been reported as $95.6 \%$ and $97.1 \%$, respectively, making this test much reliable than QFT-GIT.11

Various studies have compared the effectiveness and coherence of TST and QFT-GIT in screening LTBI in children. ${ }^{12,13}$ However, studies on T-SPOT.TB are lacking. In this study, we aimed to analyze the coherence between T-SPOT.TB and TST with different cut-off values in screening LTBI both prior to and at the sixth month of anti-TNF treatment.

\section{PATIENTS AND METHODS}

This study was conducted prospectively in four tertiary Pediatric Pulmonology Centers in Turkey between December 2015 and March 2017. The study protocol was approved by the University of Health Sciences, Dr. Lutfi Kirdar Research and Training Hospital Ethics Committee. A written informed consent was obtained from all subjects' families. The study was conducted in accordance with the principles of the Declaration of Helsinki.

A total of 57 pediatric patients (34 girls, 23 boys, mean age $12.4 \pm 3.9$ years; range, 6 to 18 years) diagnosed with IMIDs and who applied to Pediatric Pulmonology Clinics to be evaluated for LTBI prior to anti-TNF drugs were included in the study. Patients were evaluated for TB with general medical history, contact history with TB, possible symptoms, physical examination, clinical findings and chest X-ray. Patients who were not considered to have active TB were included in the study to be screened for LTBI. Patients who had history of TB treatment, LTBI prophylaxis or prior anti-TNF drug use were excluded.

All patients were evaluated with both TST and T-SPOT.TB for LTBI screening prior to anti-TNF therapy. TST results were evaluated according to the current Turkish guidelines at the time of the study. ${ }^{14}$ These guidelines suggest using TST for screening LTBI and all patients' TST results should be accepted positive if $\geq 5 \mathrm{~mm}$ and negative if $<5 \mathrm{~mm}$. All patients with positive TST results $(\geq 5 \mathrm{~mm})$ and positive T-SPOT.TB results in our study were given chemoprophylaxis. All patients were reevaluated with both TST and T-SPOT.TB at the sixth month of anti-TNF treatment. Coherence between TST and T-SPOT. TB results was evaluated. Besides, coherence between T-SPOT.TB results and other possible TST cut-off values that are not suggested by the guidelines (TST: 5-9 mm; TST: 10-15 mm and TST $\geq 15 \mathrm{~mm}$ ) were also evaluated.

Patient information about the IMID, names and time periods of DMARDs and glucocorticoid dosage that were used before, time span since the disease diagnosis and type of anti-TNF drug to be started were recorded to evaluate patient characteristics. Low-dose glucocorticoid therapy was defined as doses lower than $0.5-2 \mathrm{mg} /$ day per $\mathrm{kg}$ body weight (or $\leq 10 \mathrm{mg} /$ day for older 
children) of prednisone or equivalent. High-dose glucocorticoid therapy was defined as $>2 \mathrm{mg}$ /day per $\mathrm{kg}$ body weight (or $10 \mathrm{mg} /$ day for older children) of prednisone or equivalent. ${ }^{15}$

All subjects were evaluated for BCG vaccination. BCG vaccination status was evaluated by checking the immunization record cards of the patients and examination of the scar.

As part of the $\mathrm{T}$-Spot.TB procedure, $8 \mathrm{~mL}$ of peripheral venous blood was collected from all subjects and processed within four hours according to manufacturer's instructions (Oxford Immunotec, Oxford, UK).

After blood collection for T-SPOT.TB, the TST was performed on the volar surface of the forearm with $0.1 \mathrm{~mL}$ (5 tuberculin units) of purified protein derivative solution according to the intradermal Mantoux method by a nurse expert in the procedure. The largest diameter of skin induration was detected with palpation and ballpoint method by the same investigators at the end of 72 hours and recorded in $\mathrm{mm}$.

For chemoprophylaxis, patients with TST $\geq 5 \mathrm{~mm}$ and/or T-SPOT.TB positivity were treated with isoniazid (INH) for nine months. INH was started at least one month before the beginning of anti-TNF treatment.

Patients were evaluated clinically every three months. Patients with any relevant symptoms, physical signs or examination findings were also evaluated with chest X-ray. All patients, whether receiving chemoprophylaxis or not, were evaluated with TST and T-SPOT.TB at the sixth month of the follow-up.

\section{Statistical analysis}

Number Cruncher Statistical System 2007 program was used for the statistical analysis (Kaysville, Utah, USA). While analyzing the data, descriptive statistics such as mean, standard deviation, frequency and ratio were used. Student's t-test was used to compare quantitative data in the comparison of the two groups' data with normal distribution. Mann-Whitney U test was performed in the comparison of the two groups without normal distribution. Pearson's Chi-squared test, Fisher's exact test and Fisher-Freeman-Halton's test were used in the comparison of the qualitative data. A $p$ value $<0.05$ was considered statistically significant. Diagnostic tests (sensitivity, specificity, positive predictive value, negative predictive value) were also calculated.

As there is no gold standard method for the diagnosis of LTBI, Cohen's kappa $(\kappa)$ is used for the evaluation of the coherence and inter-rater agreement between TST and T-SPOT.TB. Kappa values are interpreted as: $\angle 0=$ no agreement, $0.0-0.20=$ poor agreement, $0.21-0.40=$ fair agreement, $0.41-0.60=$ moderate agreement, $0.61-0.80=$ good agreement, $0.81-1.0=$ perfect agreement. $^{16}$

\section{RESULTS}

A total of 60 patients applied to the clinics for screening prior to anti-TNF therapy. Two patients with history of chemoprophylaxis and one patient with prior anti-TNF use were excluded and the remaining 57 patients were included. All 57 patients concluded the study's follow-up period of six months. Of the patient population, 59.6\% $(n=34)$ were girls and $40.4 \%(n=23)$ were boys. Patients' IMID diagnoses were juvenile idiopathic arthritis (JIA) in 78.7\% ( $\mathrm{n}=45)$, systemic sclerosis in $8.7 \%(n=5)$, spondyloarthropathies in $7 \%(n=4)$ and systemic lupus erythematosus in 5.3\% $(n=3)$. Other patient characteristics and drug use were summarized in Table 1.

All patients were vaccinated with BCG and had one scar. Prior to anti-TNF treatment, in the first evaluation, TST results were $<5 \mathrm{~mm}$ in $71.9 \%$ $(\mathrm{n}=41), 5-9 \mathrm{~mm}$ in $10.5 \%(\mathrm{n}=6), 10-14 \mathrm{~mm}$ in $10.5 \%(\mathrm{n}=6)$ and $\geq 15 \mathrm{~mm}$ in $7.1 \%(\mathrm{n}=4)$ of the patients. With TST cut-off $\geq 5 \mathrm{~mm}, 71.9 \%$ ( $\mathrm{n}=41)$ had negative and $28.1 \%(n=16)$ had positive TST results in the first evaluation.

There was no statistically significant difference in TST positivity rates between the patient groups with or without glucocorticoid use (for both low dose and high dose glucocorticoid use), patient groups using different DMARDs and patient groups who were planned to use different antiTNFs. Also, no difference was detected in T-SPOT. TB positivity rates when evaluated between the same groups.

At the sixth month of anti-TNF treatment, TST scores were $<5 \mathrm{~mm}$ in $66.7 \%(\mathrm{n}=38), 5-9 \mathrm{~mm}$ in $14 \%(\mathrm{n}=8), 10-14 \mathrm{~mm}$ in $10.5 \%(\mathrm{n}=6)$ and $\geq 15 \mathrm{~mm}$ 


\begin{tabular}{|c|c|c|c|}
\hline & $\mathrm{n}$ & $\%$ & Mean \pm SD \\
\hline Age (year) & & & $12.4 \pm 3.9$ \\
\hline \multicolumn{4}{|l|}{ Sex } \\
\hline Female & 34 & 59.6 & \\
\hline Male & 23 & 40.4 & \\
\hline \multicolumn{4}{|l|}{ IMID } \\
\hline Juvenile idiopathic arthritis & 45 & 78.7 & \\
\hline Systemic sclerosis & 5 & 8.7 & \\
\hline Spondyloarthropathies & 4 & 7.0 & \\
\hline Systemic lupus erythematosus & 3 & 5.3 & \\
\hline Time span from IMID diagnosis (year) & & & $3.4 \pm 2.3$ \\
\hline \multicolumn{4}{|l|}{ Glucocorticoid use } \\
\hline No & 13 & 22.8 & \\
\hline Yes & 44 & 77.2 & \\
\hline Duration of glucocorticoid treatment (month) & & & $23.2 \pm 19.7$ \\
\hline \multicolumn{4}{|l|}{ Glucocorticoids } \\
\hline Low dose & 30 & 68.2 & \\
\hline High dose & 14 & 31.8 & \\
\hline \multicolumn{4}{|l|}{ DMARDs } \\
\hline No & 8 & 14.0 & \\
\hline Yes & 49 & 86.0 & \\
\hline Methotrexate & 40 & 81.6 & \\
\hline Tacrolimus & 3 & 6.1 & \\
\hline Azathioprine & 3 & 6.1 & \\
\hline Colchicine & 2 & 4.1 & \\
\hline Sulfasalazine & 1 & 2.1 & \\
\hline Duration of DMARD use (month) & & & $26.4 \pm 20.2$ \\
\hline \multicolumn{4}{|l|}{ Anti-TNF type } \\
\hline Adalimumab & 4 & 7.0 & \\
\hline Etanercept & 51 & 89.5 & \\
\hline Infliximab & 2 & 3.5 & \\
\hline
\end{tabular}

in $8.8 \%(\mathrm{n}=5)$ of the patients. At the sixth month, $66.7 \%(n=38)$ had negative and 33.3\% $(n=19)$ had positive TST results for $\geq 5 \mathrm{~mm}$ cut-off (Table 2 ).
Three patients with negative TST results at the beginning had positive results at the sixth month of anti-TNF treatment. Two of these patients'

Table 2. Tuberculin skin test results prior to and at sixth month of anti-TNF treatment

\begin{tabular}{lccc}
\hline & TST induration & $\mathrm{n}$ & $\%$ \\
\hline Prior to treatment $(\mathrm{mm})$ & $<5$ & 41 & 71.9 \\
& $5-9$ & 6 & 10.5 \\
& $10-14$ & 6 & 10.5 \\
Total & $\geq 15$ & 4 & 7.1 \\
& Negative & 41 & 71.9 \\
Sixth month of treatment $(\mathrm{mm})$ & Positive* & 16 & 28.1 \\
& $<5$ & 38 & 66.7 \\
& $5-9$ & 8 & 14.0 \\
Total & $10-14$ & 6 & 10.5 \\
& $\geq 15$ & 5 & 8.8 \\
& Negative & 38 & 66.7 \\
TNF: Tumor necrosis factor; TST: Tuberculin skin test; * Tuberculin skin test cut-off $\geq 5 \mathrm{~mm}$.
\end{tabular}




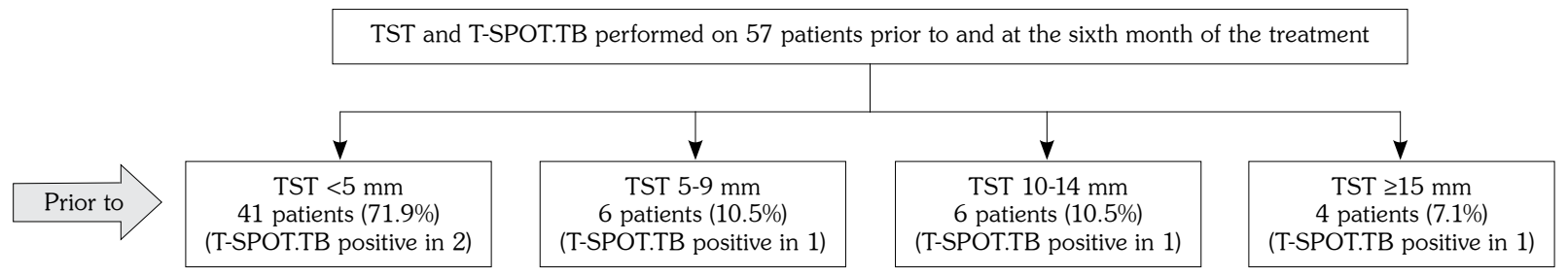

Patients diagnosed with LTBI: 18 (31.5\%) (13: TST positive only, 3: Both TST and T-SPOT.TB positive, 2: T-Spot.TB test positive only

\begin{tabular}{|c|c|c|c|c|}
\hline $6^{\text {th }}$ month & $\begin{array}{c}\text { TST }<5 \mathrm{~mm} \\
38 \text { patients }(66.7 \%) \\
\text { (T-SPOT.TB positive none) }\end{array}$ & $\begin{array}{c}\text { TST } 5-9 \mathrm{~mm} \\
8 \text { patients }(14 \%) \\
\text { (T-SPOT.TB positive in } 2 \text { ) }\end{array}$ & $\begin{array}{c}\text { TST } 10-14 \mathrm{~mm} \\
6 \text { patients }(10.5 \%) \\
\text { (T-SPOT.TB positive in } 1 \text { ) }\end{array}$ & $\begin{array}{c}\text { TST } \geq 15 \mathrm{~mm} \\
5 \text { patients }(8.8 \%) \\
\text { (T-SPOT.TB positive in } 2 \text { ) }\end{array}$ \\
\hline
\end{tabular}

New LTBI diagnosis in 3 patients (TST seroconversion 3/41: 7.5\%)

Total LTBI diagnosis: 19 (33.3\%) (14: TST positive only, 5: Both TST and T-SPOT.TB positive)

Figure 1. Patient results prior to and at sixth month of anti-tumor necrosis factor treatment.

T-SPOT.TB: T-SPOT tuberculosis test; TST: Tuberculin skin test; LTBI: Latent tuberculosis infection.

TST resulted 5-9 $\mathrm{mm}$ and the other one resulted $\geq 15 \mathrm{~mm}$. None of these patients with increased TST results on the sixth month (seroconversion) developed active TB (Figure 1).

T-SPOT.TB test was negative in $91.2 \%(n=52)$ and positive in $8.8 \%(\mathrm{n}=5)$ of the patients both prior to and at the sixth month of the treatment (Table 3).

In the evaluation prior to the treatment when TST cut-off was accepted as $\geq 5 \mathrm{~mm}$, TST positivity was $28.1 \%(n=16)$ and T-SPOT.TB positivity was $8.8 \%(n=5)$. There was poor coherence between T-SPOT.TB results and TST results when TST cut-off was accepted as $5 \mathrm{~mm}$ and also for all different possible cut-off values (Table 4).

In the evaluation on the sixth month of anti-TNF treatment when TST cut-off value was accepted as $\geq 5 \mathrm{~mm}$, TST was positive in $33.3 \%$ $(n=19)$ and T-SPOT.TB was positive in $8.8 \%$ $(n=5)$. The coherence between T-SPOT.TB results and TST results for all different cut-off values was poor or fair (Table 5).

\section{DISCUSSION}

This study aimed to analyze the coherence between TST results and T-SPOT.TB results in patients with IMID prior to and on the sixth month of anti-TNF therapy. It is well known that use of anti-TNF drugs increases LTBI risk 10 to 20 times. ${ }^{17,18}$ Also, presence of an autoimmune disease and anti-TNF drug use combined with or consecutively with other anti-rheumatic drugs increase this risk more than anti-TNF use alone. ${ }^{19}$

Table 3. Evaluation of T-SPOT.TB test results prior to and at sixth month of anti-TNF treatment in comparison to TST results

\begin{tabular}{|c|c|c|c|c|c|c|c|c|c|c|}
\hline & \multicolumn{2}{|c|}{ Negative } & \multicolumn{2}{|c|}{ Positive* } & \multirow[b]{2}{*}{$\kappa$} & \multirow[b]{2}{*}{ Sensitivity } & \multirow[b]{2}{*}{ Specificity } & \multirow[b]{2}{*}{$\begin{array}{c}\text { Positive } \\
\text { predictive } \\
\text { value }\end{array}$} & \multirow[b]{2}{*}{$\begin{array}{c}\text { Negative } \\
\text { predictive } \\
\text { value }\end{array}$} & \multirow[b]{2}{*}{ Accuracy } \\
\hline & $\mathrm{n}$ & $\%$ & $\mathrm{n}$ & $\%$ & & & & & & \\
\hline T-SPOT.TB & 52 & 91.2 & 5 & 8.8 & \multirow{2}{*}{0.176} & \multirow{2}{*}{60.00} & \multirow{2}{*}{75.00} & \multirow{2}{*}{18.75} & \multirow{2}{*}{95.12} & \multirow{2}{*}{73.68} \\
\hline TST prior to & 41 & 71.9 & 16 & 28.1 & & & & & & \\
\hline T-SPOT.TB & 52 & 91.2 & 5 & 8.8 & \multirow{2}{*}{0.129} & \multirow{2}{*}{60.00} & \multirow{2}{*}{69.23} & \multirow{2}{*}{15.79} & \multirow{2}{*}{94.74} & \multirow{2}{*}{68.42} \\
\hline TST sixth month & 38 & 66.7 & 19 & 33.3 & & & & & & \\
\hline
\end{tabular}


Table 4. Prior to treatment: comparison and coherence of T-SPOT tuberculosis test with different cut-off values of TST

\begin{tabular}{|c|c|c|c|c|c|c|c|c|c|c|}
\hline & \multicolumn{2}{|c|}{ Negative } & \multicolumn{2}{|c|}{ Positive } & \multirow[b]{2}{*}{$\kappa$} & \multirow[b]{2}{*}{ Sensitivity } & \multirow[b]{2}{*}{ Specificity } & \multirow[b]{2}{*}{$\begin{array}{l}\text { Positive } \\
\text { predictive } \\
\text { value }\end{array}$} & \multirow[b]{2}{*}{$\begin{array}{c}\text { Negative } \\
\text { predictive } \\
\text { value }\end{array}$} & \multirow[b]{2}{*}{ Accuracy } \\
\hline & $\mathrm{n}$ & $\%$ & $\mathrm{n}$ & $\%$ & & & & & & \\
\hline $\begin{array}{l}\text { T-SPOT.TB } \\
\text { TST ( } \geq 5 \mathrm{~mm})\end{array}$ & $\begin{array}{l}52 \\
41\end{array}$ & $\begin{array}{l}91.2 \\
71.9\end{array}$ & $\begin{array}{c}5 \\
16\end{array}$ & $\begin{array}{c}8.8 \\
28.1\end{array}$ & 0.176 & 60.00 & 75.00 & 18.75 & 95.12 & 73.68 \\
\hline $\begin{array}{l}\text { T-SPOT.TB } \\
\text { TST (5-9 mm) }\end{array}$ & $\begin{array}{l}44 \\
41\end{array}$ & $\begin{array}{l}93.6 \\
87.2\end{array}$ & $\begin{array}{l}3 \\
6\end{array}$ & $\begin{array}{c}6.4 \\
12.8\end{array}$ & 0.150 & 33.33 & 88.64 & 16.67 & 95.12 & 85.11 \\
\hline $\begin{array}{l}\text { T-SPOT.TB } \\
\text { TST }(10-14 \mathrm{~mm})\end{array}$ & $\begin{array}{l}49 \\
47\end{array}$ & $\begin{array}{l}92.5 \\
88.7\end{array}$ & $\begin{array}{l}4 \\
6\end{array}$ & $\begin{array}{c}7.5 \\
11.3\end{array}$ & 0.120 & 25.00 & 89.80 & 16.67 & 93.62 & 84.91 \\
\hline $\begin{array}{l}\text { T-SPOT.TB } \\
\text { TST ( } \geq 15 \mathrm{~mm})\end{array}$ & $\begin{array}{l}52 \\
53\end{array}$ & $\begin{array}{l}91.2 \\
93.0\end{array}$ & $\begin{array}{l}5 \\
4\end{array}$ & $\begin{array}{l}8.8 \\
7.0\end{array}$ & 0.156 & 20.00 & 94.23 & 25.00 & 92.45 & 87.72 \\
\hline
\end{tabular}

T-SPOT.TB: T-SPOT tuberculosis test; TST: Tuberculin skin test.

Table 5. At sixth month of treatment: comparison and coherence of T-SPOT tuberculosis test with different cut-off values of TST

\begin{tabular}{|c|c|c|c|c|c|c|c|c|c|c|}
\hline & \multicolumn{2}{|c|}{ Negative } & \multicolumn{2}{|c|}{ Positive* } & \multirow[b]{2}{*}{$\kappa$} & \multirow[b]{2}{*}{ Sensitivity } & \multirow[b]{2}{*}{ Specificity } & \multirow[b]{2}{*}{$\begin{array}{l}\text { Positive } \\
\text { predictive } \\
\text { value }\end{array}$} & \multirow[b]{2}{*}{$\begin{array}{l}\text { Negative } \\
\text { predictive } \\
\text { value }\end{array}$} & \multirow[b]{2}{*}{ Accuracy } \\
\hline & $\mathrm{n}$ & $\%$ & $\mathrm{n}$ & $\%$ & & & & & & \\
\hline $\begin{array}{l}\text { T-SPOT.TB } \\
\text { TST ( } \geq 5 \mathrm{~mm})\end{array}$ & $\begin{array}{l}52 \\
38\end{array}$ & $\begin{array}{l}91.2 \\
66.7\end{array}$ & $\begin{array}{c}5 \\
19\end{array}$ & $\begin{array}{c}8.8 \\
33.3\end{array}$ & 0.129 & 60.00 & 69.23 & 15.79 & 94.74 & 68.42 \\
\hline $\begin{array}{l}\text { T-SPOT.TB } \\
\text { TST (5-9 mm) }\end{array}$ & $\begin{array}{l}44 \\
38\end{array}$ & $\begin{array}{l}95.7 \\
82.6\end{array}$ & $\begin{array}{l}2 \\
8\end{array}$ & $\begin{array}{c}4.3 \\
17.4\end{array}$ & - & 0 & 81.82 & 0 & 94.74 & 78.26 \\
\hline $\begin{array}{l}\text { T-SPOT.TB } \\
\text { TST }(10-14 \mathrm{~mm})\end{array}$ & $\begin{array}{l}48 \\
46\end{array}$ & $\begin{array}{l}92.3 \\
88.5\end{array}$ & $\begin{array}{l}4 \\
6\end{array}$ & $\begin{array}{c}7.7 \\
11.5\end{array}$ & 0.339 & 50.00 & 91.67 & 33.33 & 95.65 & 88.46 \\
\hline $\begin{array}{l}\text { T-SPOT.TB } \\
\text { TST ( } \geq 15 \mathrm{~mm})\end{array}$ & $\begin{array}{l}52 \\
52\end{array}$ & $\begin{array}{l}91.2 \\
91.2\end{array}$ & $\begin{array}{l}5 \\
5\end{array}$ & $\begin{array}{l}8.8 \\
8.8\end{array}$ & 0.123 & 20.00 & 92.00 & 20.00 & 92.00 & 85.45 \\
\hline
\end{tabular}

Diagnosing LTBI is challenging particularly in immunocompromised patients. ${ }^{20,21}$ Several studies reported that TST responses are much lower in pediatric patients with rheumatologic diseases. A study compared TST results in 115 children with JIA and 45 healthy controls and found decreased TST responses in children with JIA than controls (TST results being $4.12 \pm 5.24 \mathrm{~mm}$ and $7.83 \pm 3.47 \mathrm{~mm}$, respectively). ${ }^{22}$ Also, Barut et al. ${ }^{23}$ studied 234 JIA patients on anti-TNF therapy and concluded that TST response is decreased in JIA patients on anti-TNF agents compared to the controls. In our study, no statistically significant difference was seen in TST positivity rates and T-SPOT.TB positivity rates between the patient groups with or without glucocorticoid use (for both low dose and high dose glucocorticoid use), patient groups using different DMARDs and patient groups who were planned to use different anti-TNFs.

Anti-tumor necrosis factor agents are considered safe in children with IMID in most of the published studies. Of the limited studies published in pediatric population, in a study conducted in Turkey, 71 children with inflammatory diseases were screened for LTBI prior to anti-TNF treatment and $8.45 \%$ of the children were diagnosed with LTBI with TST cut-off value $\geq 15 \mathrm{~mm}$ and/or QFT-GIT positivity. ${ }^{24}$ In our study, we used current local guidelines which suggest TST cut-off value $\geq 5 \mathrm{~mm}$ and/or T-SPOT.TB positivity and diagnosed 18 (31.5\%) 
of our patients with LTBI. Difference between LTBI rates is obviously the result of different TST cut-off values. Another Turkish study evaluated 144 children with chronic rheumatologic diseases on anti-TNF drugs, and on the follow-ups, $4.8 \%$ of the patients had TST seroconversion to positivity and received INH prophylaxis for nine months, while only one patient developed active TB and received antituberculosis therapy with three drugs. ${ }^{25}$ In our study, at the sixth month evaluation, seroconversion in TST results were seen in three cases (3/41) similarly with the rate of $7.3 \%$. These cases were T-SPOT.TB negative and none developed active TB.

A study tested adults with rheumatic diseases with T-SPOT.TB and TST. In that study, history of BCG was associated with the discordance in TST positive and T-SPOT.TB negative patients. Glucocorticoid use was associated with TST negative and T-SPOT.TB positive discordance. ${ }^{26}$ Another study found poor coherence between TST and QFT-GIT results in adults for LTBI screening before anti-TNFs. ${ }^{12} \mathrm{~A}$ study comparing TST and QFT-GIT for LTBI detection in pediatric JIA patients also found poor coherence between two tests both in the patient and control groups. That study found an inverse proportion between positivity in TST results and JIA disease activity concluding that the discordance between the two tests could be the result of disease activity for the patient group and BCG vaccination for the control group. ${ }^{13}$ In our study, all subjects were vaccinated with BCG. Poor coherence was found between TST positivity and T-SPOT.TB positivity for any TST cut-off values both prior to and at the sixth month of the therapy. Of the 41 patients with negative TST at the beginning, two patients had positive T-SPOT.TB results. All of our patients had active disease to be started on anti-TNFs and $77.2 \%$ of our patients had received glucocorticoid therapy. Disease activity and glucocorticoid therapy can explain this discordance. Of the 16 patients with positive TST results prior to anti-TNFs, only three had T-SPOT.TB positivity. This discordance is possibly because of the BCG status of our patients. Discordance between the tests may also be caused by the limited sample size of the study group. New studies are needed with larger patient groups that can compare vaccinated and non-vaccinated patients.
To our knowledge, our study is the first to compare TST and T-SPOT.TB results in pediatric population for LTBI screening prior to anti-TNF therapy. It has been advantageous to use T-SPOT. TB as the IGRA method in the study; since unlike QFT-GIT, T-SPOT.TB does not give any indeterminate results, is not affected by age and has higher specificity and sensitivity. ${ }^{27-29}$

Different guidelines suggest different cut-off values for TST positivity in LTBI screening prior to anti-TNFs. American Thoracic Society guidelines published in 2017 state that there is insufficient data to recommend TST or IGRA and advise using a cut-off value $\geq 5 \mathrm{~mm}$ if TST is used. ${ }^{30}$ On the other hand, the Tuberculosis Network European Trials Group consensus statement suggests using a TST cut-off value $\geq 10 \mathrm{~mm} .{ }^{31}$ Most recent guidelines published by Turkish Ministry of Health after the completion of our study recommend using either an IGRA test or TST with cut-off value $\geq 5 \mathrm{~mm}$ for nonvaccinated and $\geq 10 \mathrm{~mm}$ for vaccinated patients. ${ }^{32}$ As there is no certainty on the TST cut-off value to be used amongst guidelines, another strength of our study is the comparison of the T-SPOT.TB results with various possible TST cut-off values. ${ }^{33}$

Major limitations of our study are the limited number of patients and the use of many different immunosuppressive drugs for different time periods particularly prior to TST testing which can be affected. However, considering that almost all patients who will receive anti-TNF therapy will already be on DMARDs or glucocorticoids, such influence on TST is almost inevitable also for further studies.

In conclusion, each country should develop its own guidelines according to the BCG status and TB disease prevalence for LTBI screening prior to anti-TNF treatment. Our results show that in our country, with all patients vaccinated, there is poor coherence between TST and T-SPOT.TB in screening both prior to and under anti-TNF treatment. Under these circumstances, it would still be rational to use both tests for screening until further studies bring new evidence on the subject.

\section{Declaration of conflicting interests}

The authors declared no conflicts of interest with respect to the authorship and/or publication of this article. 


\section{Funding}

The authors received no financial support for the research and/or authorship of this article.

\section{REFERENCES}

1. Ellerin T, Rubin RH, Weinblatt ME. Infections and anti-tumor necrosis factor alpha therapy. Arthritis Rheum 2003;48:3013-22.

2. Kroesen S, Widmer AF, Tyndall A, Hasler P. Serious bacterial infections in patients with rheumatoid arthritis under anti-TNF-alpha therapy. Rheumatology (Oxford) 2003;42:617-21.

3. Long R, Gardam M. Tumour necrosis factor-alpha inhibitors and the reactivation of latent tuberculosis infection. CMAJ 2003;168:1153-6.

4. Huebner RE, Schein MF, Bass JB Jr. The tuberculin skin test. Clin Infect Dis 1993;17:968-75.

5. Targeted tuberculin testing and treatment of latent tuberculosis infection. This official statement of the American Thoracic Society was adopted by the ATS Board of Directors, July 1999. This is a Joint Statement of the American Thoracic Society (ATS) and the Centers for Disease Control and Prevention (CDC). This statement was endorsed by the Council of the Infectious Diseases Society of America. (IDSA), September 1999, and the sections of this statement. Am J Respir Crit Care Med 2000;161:S221-47.

6. Hanta I, Ozbek S, Kuleci S, Seydaoglu G, Ozyilmaz E. Detection of latent tuberculosis infection in rheumatologic diseases before anti-TNF $\alpha$ therapy: tuberculin skin test versus IFN- $\gamma$ assay. Rheumatol Int 2012;32:3599-603.

7. Farhat M, Greenaway C, Pai M, Menzies D. Falsepositive tuberculin skin tests: what is the absolute effect of BCG and non-tuberculous mycobacteria? Int J Tuberc Lung Dis 2006;10:1192-204.

8. Lalvani A, Millington KA. T cell-based diagnosis of childhood tuberculosis infection. Curr Opin Infect Dis 2007;20:264-71.

9. Marques CD, Duarte ÂL, de Lorena VM, Souza JR, Souza WV, Gomes Yde M, et al. Evaluation of an interferon gamma assay in the diagnosis of latent tuberculosis infection in patients with rheumatoid arthritis. Rheumatol Int 2009;30:57-62.

10. Rangaka MX, Wilkinson KA, Glynn JR, Ling D, Menzies D, Mwansa-Kambafwile J, et al. Predictive value of interferon- $\gamma$ release assays for incident active tuberculosis: a systematic review and meta-analysis. Lancet Infect Dis 2012;12:45-55.

11. Domínguez J, Ruiz-Manzano J, De Souza-Galvão M, Latorre I, Milà C, Blanco S, et al. Comparison of two commercially available gamma interferon blood tests for immunodiagnosis of tuberculosis. Clin Vaccine Immunol 2008;15:168-71.
12. Cobanoglu N, Ozcelik U, Kalyoncu U, Ozen S, Kiraz $\mathrm{S}$, Gurcan $\mathrm{N}$, et al. Interferon-gamma assays for the diagnosis of tuberculosis infection before using tumour necrosis factor-alpha blockers. Int $J$ Tuberc Lung Dis 2007;11:1177-82.

13. Camlar SA, Makay B, Appak O, Appak YC, Esen N, Günay $T$, et al. Performance of tuberculin skin test and interferon gamma assay for the diagnosis of latent tuberculosis infection in juvenile idiopathic arthritis. Clin Rheumatol 2011;30:1189-93.

14. Kalfa M, Aksu K. Treatment with tumor necrosis factor-alpha antagonists and infections. RAED Journal 2011;3:49-56.

15. Heijstek MW, Ott de Bruin LM, Bijl M, Borrow R, van der Klis F, Koné-Paut I, et al. EULAR recommendations for vaccination in paediatric patients with rheumatic diseases. Ann Rheum Dis 2011;70:1704-12.

16. Landis JR, Koch GG. The measurement of observer agreement for categorical data. Biometrics 1977;33:159-74.

17. Tubach F, Salmon D, Ravaud P, Allanore Y, Goupille $\mathrm{P}$, Bréban $\mathrm{M}$, et al. Risk of tuberculosis is higher with anti-tumor necrosis factor monoclonal antibody therapy than with soluble tumor necrosis factor receptor therapy: The three-year prospective French Research Axed on Tolerance of Biotherapies registry. Arthritis Rheum 2009;60:1884-94.

18. Dixon WG, Hyrich KL, Watson KD, Lunt M, Galloway J, Ustianowski A. Drug-specific risk of tuberculosis in patients with rheumatoid arthritis treated with anti-TNF therapy: results from the British Society for Rheumatology Biologics Register (BSRBR). Ann Rheum Dis 2010;69:522-8.

19. Yasui K. Immunity against Mycobacterium tuberculosis and the risk of biologic anti-TNF- $\alpha$ reagents. Pediatr Rheumatol Online J 2014;12:45.

20. Menzies D, Pai M, Comstock G. Metaanalysis: new tests for the diagnosis of latent tuberculosis infection: areas of uncertainty and recommendations for research. Ann Intern Med 2007;146:340-54.

21. Mazurek GH, Jereb J, Vernon A, LoBue P, Goldberg $\mathrm{S}$, Castro K. Updated guidelines for using Interferon Gamma Release Assays to detect Mycobacterium tuberculosis infection - United States, 2010. MMWR Recomm Rep 2010;59:1-25.

22. Kiray E, Kasapcopur O, Bas V, Kamburoglu-Goksel A, Midilli K, Arisoy N, et al. Purified protein derivative response in juvenile idiopathic arthritis. $\mathrm{J}$ Rheumatol 2009;36:2029-32.

23. Barut K, Şahin S, Adrovic A, Köşker M, Kıllıç Ö, Camcıoğlu Y, et al. Tuberculin skin test response in patients with juvenile idiopathic arthritis on anti-TNF therapy Turk J Med Sci 2018;48:1109-14.

24. Atikan BY, Cavusoglu C, Dortkardesler M, Sozeri B. Assessment of tuberculosis infection during treatment with biologic agents in a BCG-vaccinated pediatric population. Clin Rheumatol 2016;35:427-31. 
25. Kilic O, Kasapcopur O, Camcioglu Y, Cokugras $\mathrm{H}$, Arisoy $\mathrm{N}$, Akcakaya N. Is it safe to use antiTNF- $\alpha$ agents for tuberculosis in children suffering with chronic rheumatic disease? Rheumatol Int 2012;32:2675-9.

26. Vassilopoulos D, Stamoulis N, Hadziyannis E, Archimandritis AJ. Usefulness of enzyme-linked immunospot assay (Elispot) compared to tuberculin skin testing for latent tuberculosis screening in rheumatic patients scheduled for anti-tumor necrosis factor treatment. J Rheumatol 2008;35:1271-6.

27. Cruz AT, Geltemeyer AM, Starke JR, Flores JA, Graviss EA, Smith KC. Comparing the tuberculin skin test and T-SPOT. TB blood test in children. Pediatrics 2011;127:31-8.

28. Abubakar I, Stagg HR, Whitworth H, Lalvani A. How should I interpret an interferon gamma release assay result for tuberculosis infection? Thorax 2013;68:298-301.

29. Janssens JP, Roux-Lombard P, Perneger T, Metzger $\mathrm{M}$, Vivien R, Rochat T. Quantitative scoring of an interferon-gamma assay for differentiating active from latent tuberculosis. Eur Respir J 2007;30:722-8.

30. Lewinsohn DM, Leonard MK, LoBue PA, Cohn DL, Daley CL, Desmond E, et al. Official American Thoracic Society/Infectious Diseases Society of America/Centers for Disease Control and Prevention Clinical Practice Guidelines: Diagnosis of Tuberculosis in Adults and Children. Clin Infect Dis 2017;64:e1-e33.

31. Solovic I, Sester M, Gomez-Reino JJ, Rieder HL, Ehlers S, Milburn HJ, et al. The risk of tuberculosis related to tumour necrosis factor antagonist therapies: a TBNET consensus statement. Eur Respir J 2010;36:1185-206.

32. Anti-TNF kullanan hastalarda tüberküloz rehberi. Ankara: TC Sağlık Bakanlığı, Türkiye Halk Sağlığı Kurumu; 2016.

33. Hasan T, Au E, Chen S, Tong A, Wong G. Screening and prevention for latent tuberculosis in immunosuppressed patients at risk for tuberculosis: a systematic review of clinical practice guidelines. BMJ Open 2018;8:e022445. 